\title{
molecules
}

ISSN 1420-3049

(C) 2007 by MDPI

Communication

www.mdpi.org/molecules

\section{Targeted Synthesis of \\ 1-(4-Hydroxyiminomethylpyridinium)-3-pyridiniumpropane Dibromide - A New Nerve Agent Reactivator}

\author{
Kamil Kuca ${ }^{1,2}$, Kamil Musilek ${ }^{2,3, *}$, Martin Paar ${ }^{3}$, Daniel Jun ${ }^{1,2}$, Petr Stodulka ${ }^{1}$, Martina \\ Hrabinova ${ }^{1}$ and Jan Marek ${ }^{2,3}$ \\ ${ }^{1}$ Center of Advanced Studies, Faculty of Military Health Sciences, Hradec Kralove, Czech Republic \\ 2 Department of Toxicology, Faculty of Military Health Sciences, Hradec Kralove, Czech Republic \\ ${ }^{3}$ Department of Pharmaceutical Chemistry and Drug Control, Faculty of Pharmacy, Hradec Kralove, \\ Czech Republic
}

* Author to whom correspondence should be addressed; E-mail: musilek@pmfhk.cz;

Tel.: 00420-973-521-523; Fax: 00420-495-518-094.

Received: 31 July 2007; in revised form: 14 August 2007 / Accepted: 14 August 2007 /

Published: 20 August 2007

\begin{abstract}
Preparation of 1-(4-hydroxy-iminomethylpyridinium)-3-pyridiniumpropane dibromide is described. This compound represents a new acetylcholinesterase (AChE) reactivator, which has no substituents on the second pyridinium ring as found in other commonly used AChE reactivators. The reactivation ability of this reactivator was tested on tabun- and cyclosarin-inhibited AChE. According to the results obtained, the new compound (without substitution and with decreased molecule size) showed increased reactivation potency in case of cyclosarin inhibited AChE. A potent oxime for treatment of tabun and cyclosarin-caused intoxications was thus obtained via slight modification of the reactivator structure (compared to trimedoxime and K027).
\end{abstract}

Keywords: Acetylcholinesterase, reactivator, nerve agent, broad-spectrum reactivator. 


\section{Introduction}

Organophosphorus inhibitors (OPI) are a large family of compounds with the common main target of action - the enzyme acetylcholinesterase (AChE; EC 3.1.1.7). These compounds irreversibly inhibit this enzyme by a covalent bond in its active site. After the inhibition, the enzyme is not able to fulfill its physiological role in an organism - splitting a neuromediator acetylcholine (ACh). Subsequently, ACh cumulates at the synaptic cleft and steadily over-stimulates nicotinic and muscarinic receptors. If no treatment is provided, a cholinergic crisis occurs and intoxicated organisms may die [1].

Nerve agents are very important group of OPI. Tabun (GA), sarin (GB), soman (GD), cyclosarin (GF) and agent VX (Figure 1) are probably the best known members of this family. Especially GB, well known after the Tokyo subway attack, has been discussed many times as a potential terrorist threat [2]. GA and GF were also discussed frequently during last the few years in connection with Iraq's possible possession of this armament [3-4].

Figure 1. Organophosphorus inhibitors of acetylcholinesterase known as nerve agents.<smiles>CCOP(=O)(C#N)N(C)C</smiles>

tabun<smiles>CC(C)OP(C)(=O)F</smiles>

sarin<smiles>CC(OP(C)(=O)F)C(C)(C)C</smiles>

soman<smiles>CP(=O)(F)OC1CCCCC1</smiles>

cyklosarin

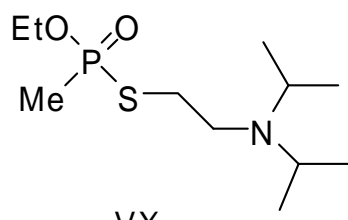

$\mathrm{VX}$

AChE oxime reactivators were developed as an antidotal treatment of OPI intoxications. Pralidoxime (1, 2-hydroxyiminomethyl-1-methylpyridinium chloride), oxime HI-6 (2, 1-(2-hydroxyiminomethylpyridinium)-3-(4-carbamoylpyridinium)-2-oxapropane dichloride), obidoxime (3, 1,3-bis(4-hydroxyiminomethylpyridinium)-2-oxapropane dichloride, Toxogonine ${ }^{\circledR}$ ) and trimedoxime $(4 ; 1,3-$ bis(4-hydroxyiminomethylpyridinium)-propane dibromide) are commercially available oxime reactivators (Figure 2) [4-6]. Reactivators with nucleophilic oxime groups are able to cleave the covalent bond between the AChE and OPI moieties and thus restore AChE activity [2].

Figure 2. Commercially available oxime reactivators.<smiles></smiles>

pralidoxime (1)

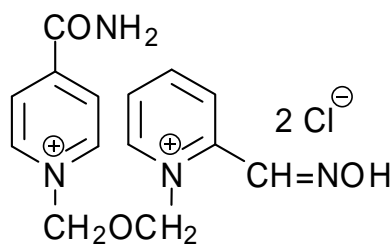

HI-6 (2)<smiles>Cn1[c-][n+](C=O)cc1</smiles>

obidoxime (3)<smiles>CCN1C=CC(C=NO)=CC=C1Cl</smiles>

trimedoxime (4)

However, currently commercially available compounds 1-4 are not sufficient [7-11] and many laboratories throughout the world are interested in the development of new AChE reactivators on account of the possible misuse of nerve agents. The promising new oxime HI-6 (1) seemed to be a 
solution, but its potency to reactivate tabun or pesticide poisoning is poor [12-16]. Due to this, new compounds are being developed and tested for their reactivation potency [17-22].

In 2003, a new promising AChE reactivator against tabun was prepared - K027 (5; Figure 3) [23]. This reactivator, together with trimedoxime (4), is considered to be currently the most potent available for experimental treatment of GA poisoning [24-27]. However, the potency of these reactivators in a case of GF poisoning was very poor [24, 28]. In this work, compound $\mathbf{6}$, a new potential cholinesterase reactivator derived from these compounds was prepared (Figure 3). Its structure was based on the removal of the functional group (trimedoxime - oxime group; K027 - carbamoyl group) on the second pyridinium ring to prevent interaction of this functional group with the enzyme cavity. A main aim was a design of a reactivator, which is able to access the enzyme active site inhibited by a bulky GF moiety. Thus, the new reactivator 1-(4-hydroxyiminomethylpyridinium)-3-pyridiniumpropane dibromide (6) was prepared.

Figure 3 Novel reactivators designed for nerve agent poisonings.

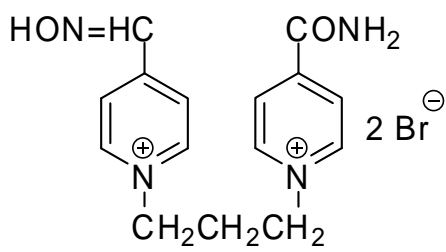

K027 (5)

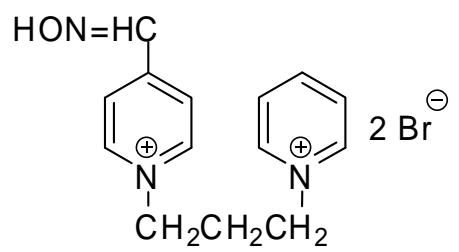

(6)

\section{Results and Discussion}

In an in vitro assay the reactivator should exceed $10 \%$ reactivation to be also able to reactivate OPI-inhibited AChE in vivo [31]. Pralidoxime (1), the reactivator available worldwide, showed a very low reactivation of the tested OPI (Table 1). Focusing on GA-inhibited AChE, there were reactivators (3-6), which fulfilled or exceed this requirement. The best tested compound for GA poisoning in vitro was trimedoxime (4) at $10^{-3} \mathrm{M}$. The other compounds were less effective, whereas the new oxime 6 was comparable with the previously prepared K027 (5) at $10^{-3} \mathrm{M}$. However, the maximal concentration attainable in vivo is $10^{-4} \mathrm{M}$. Consequently, only the new reactivator 6 was able to exceed the required limit at a concentration attainable in vivo $\left(10^{-5} \mathrm{M}\right)$ for GA intoxication.

For GF-inhibited AChE, only two oximes $(2,6)$ had any effective reactivation potency, while the best oximes for GA-inhibited AChE (3-4) were ineffective. Although the oxime HI-6 (2) showed massive reactivation of GF-inhibited AChE at both tested concentrations, it was almost ineffective against GA intoxication. In comparison with other tested reactivators, the new oxime $\mathbf{6}$ had promising potency both against GA and GF poisoning at concentrations attainable in vivo.

The SAR requirements of potent reactivators for GA-inhibited AChE were previously determined [32-33]. Thus, the bisquaternary reactivators with the oxime group at the 4-position on heteroaromatic ring and a connecting linker ranging from 3 to 4 carbon-carbon bonds were recommended. The tested reactivators (3-6) fulfilled the mentioned recommendation completely. 
Table 1. In vitro screening results (reactivation of tabun and cyclosarin inhibited acetylcholinesterase; source of the enzyme - rat brain acetylcholinesterase; nerve agents used - tabun and cyclosarin; time of inhibition by nerve agent - $10 \mathrm{~min}$; time of reactivation - $30 \mathrm{~min}$; $\mathrm{pH} 7.6$; $25^{\circ} \mathrm{C}$ ).

Nerve agent

\begin{tabular}{ccccc}
\hline & \multicolumn{2}{c}{ tabun } & \multicolumn{2}{c}{ cyclosarin } \\
\hline Oxime & Reactivation potency [\%] \pm SD & Reactivation potency [\%] \pm SD \\
\hline pralidoxime (1) & $10^{-5} \mathrm{M}$ & $10^{-3} \mathrm{M}$ & $10^{-5} \mathrm{M}$ & $10^{-3} \mathrm{M}$ \\
HI-6 (2) & $4 \pm 0$ & $4 \pm 0$ & 0 & $4 \pm 0$ \\
obidoxime (3) & $3 \pm 0$ & $2 \pm 0$ & $71 \pm 3$ & $70 \pm 3$ \\
trimedoxime (4) & $6 \pm 0$ & $25 \pm 1$ & $2 \pm 0$ & 0 \\
K027 (5) & $1 \pm 0$ & $41 \pm 2$ & 0 & 0 \\
6 & $13 \pm 0$ & $11 \pm 0$ & 0 & $21 \pm 1$ \\
\hline
\end{tabular}

However, the GF inhibition demands other features in the reactivator molecule and SAR requirements are different from those of inhibition by GA. Bisquaternary reactivators with one oxime in the 2-position of the heteroaromatic ring and a connecting linker ranging from 3 to 4 carbon-carbon bonds were recommended. Oxime HI-6 (2), which was the best from all tested reactivators against GF, fulfilled the mentioned recommendation. Surprisingly, the new oxime $\mathbf{6}$ had modest potency against GF-inhibited AChE with an oxime in the 4-position of the pyridinium ring. This finding may be hypothetically explained by loss of a functional group on the second pyridinium ring, which is not included in the reactivation process and interacts with the enzyme. Consequently, a smaller reactivator molecule could better attack the bulky GF moiety in the enzyme active site. Nevertheless, the reactivation process in GF-inhibited AChE should be further described by molecular modeling or crystal structure methods [34-35].

\section{Conclusions}

In conclusion, a new cholinesterase reactivator without any substitution on the second pyridinium ring and thus different from other commonly used reactivators was prepared. Its reactivation of GAinhibited AChE was comparable to that achieved with K027, whereas it exceeded the reactivation potency of obidoxime and trimedoxime against GF-inhibited AChE in vitro. The results confirmed that only one oxime functional group is sufficient for reactivation. The other functional groups do not appear to be necessary in a reactivator molecule. 


\section{Experimental}

\section{General}

HPLC (P200 gradient pump - Spectra-Physics Analytical, Fremont, USA; 7125 injection valve10 ul loop - Rheodyne, Cotati, USA; UV1000 detector - Spectra-Physics Analytical, Fremont, USA; CSW Chromatography Station 1.5 software - DataApex, Praha, Czech Republic; 250x4 mm I.D. Lichrospher 60 RP-select B (5 $\mu \mathrm{m})$ column - Merck, Darmstadt, Germany) and ${ }^{1} \mathrm{H}-\mathrm{NMR}$ (Varian Gemini 300; ${ }^{1} \mathrm{H}$ at $300 \mathrm{MHz},{ }^{13} \mathrm{C}$ at $75 \mathrm{MHz}$, Palo Alto CA, USA). The purities of the reaction intermediate 6a and the final product $\mathbf{6}$ were analyzed using TLC (DC-Alufolien Cellulose F; Merck, Germany; mobile phase $\mathrm{BuOH}-\mathrm{CH}_{3} \mathrm{COOH}-\mathrm{H}_{2} \mathrm{O}$ 5:1:2; detection by solution of Dragendorff reagent).

\section{Synthesis}

Novel reactivator 6 cannot be prepared in a one step synthesis due to the possible creation of a bisquaternary symmetrical byproduct (6A-6B - examples of side products; Scheme 1), which are very difficult to separate.

Scheme 1. Proposed products via one step synthesis of bisquaternary non-symmetrical acetylcholinesterase reactivator.

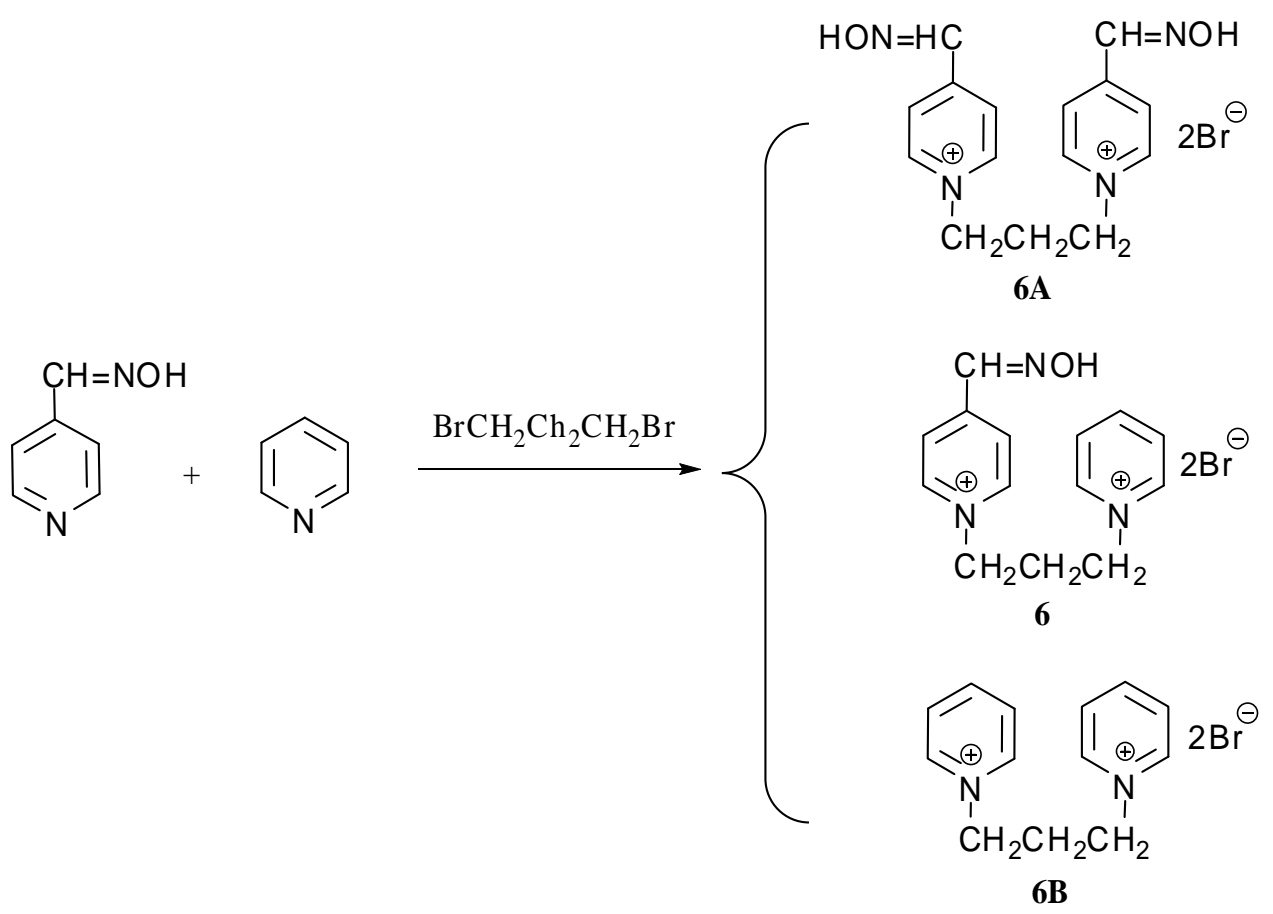

Consequently, a two-step synthesis of the proposed compound was used (Scheme 2). In the first step, monoquaternary salt 6a was prepared using very mild conditions (acetone reflux; five molar excess of alkylating chain) to decrease the creation of bisquaternary salts 6A-6B [29]. Owing to the mild conditions, the final yield (71 \%) was not as high as was expected. In the second step, the monoquaternary salt 4 was dissolved in $\mathrm{DMF}\left(80^{\circ} \mathrm{C}\right)$ with pyridine (monoquaternary salt to pyridine - 
1:2) giving proposed product 6 in a satisfactory yield (93\%). The overall two-step reaction yield was $66 \%$, the first reaction being the yield-limiting step.

Scheme 2. Two step synthesis of non-symmetrical acetylcholinesterase reactivator.

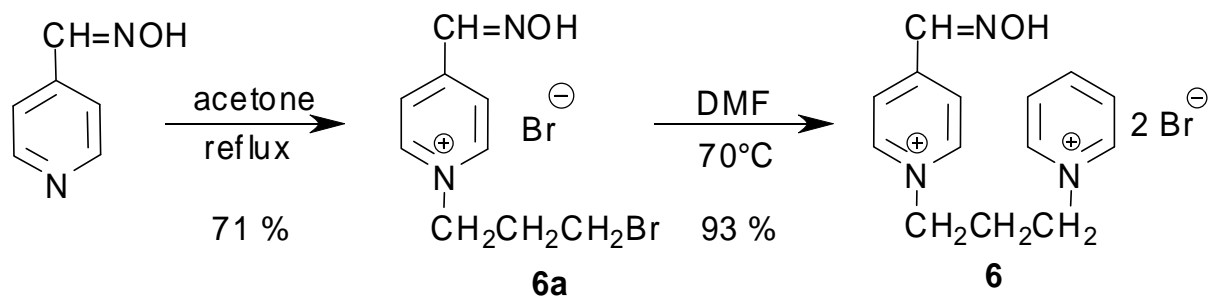

\section{Characterization data}

1-(3-Bromopropane)-4-hydroxyiminopyridinium bromide (6a): m.p. $178-181^{\circ} \mathrm{C}$; ${ }^{1} \mathrm{H}-\mathrm{NMR}$ (DMSO$\mathrm{d}_{6}$ ): 2.48 (m, $\left.2 \mathrm{H}, \underline{\mathrm{BrCH}}_{2}\right) ; 3.57$ (t, $J=6.60 \mathrm{~Hz}, 2 \mathrm{H}, \underline{\mathrm{CH}_{2}} \mathrm{CH}_{2} \mathrm{Br}$ ); 4.68 (t, $J=7.15 \mathrm{~Hz}, 2 \mathrm{H}, \mathrm{CH}_{2} \underline{\mathrm{CH}}_{2} \mathrm{~N}$ ); $8.23\left(\mathrm{~d}, J_{3,2}=J_{5,6}=6.87 \mathrm{~Hz}, 2 \mathrm{H}, \mathrm{H}-3,5\right) ; 8.43(\mathrm{~s}, 1 \mathrm{H}, \underline{\mathrm{CH}}=\mathrm{NOH}) ; 9.06\left(\mathrm{~d}, J_{2,3}=J_{6,5}=6.00 \mathrm{~Hz}, 2 \mathrm{H}, \mathrm{H}-\right.$ 2,6); HPLC: $\mathrm{R}_{\mathrm{t}}=9,56 \mathrm{~min}$.

1-(4-Hydroxyiminomethylpyridinium)-3-(pyridinium) propane dibromide (6): m.p. $241-243{ }^{\circ} \mathrm{C} ;{ }^{1} \mathrm{H}-$

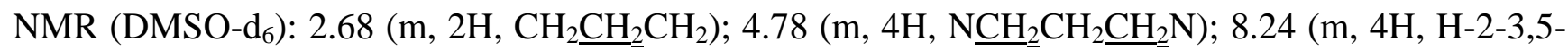
6); $8.48(\mathrm{~s}, 1 \mathrm{H},-\underline{\mathrm{CH}}=\mathrm{NOH})$ ); $8.64(\mathrm{t}, 1 \mathrm{H}, \mathrm{H}-4) ; 9.18\left(\mathrm{~d}, J_{2,3}=J_{6,5}=6.61 \mathrm{~Hz}, 2 \mathrm{H}, \mathrm{H}-2,6\right) ; 9.24\left(\mathrm{~d}, J_{3,2}=\right.$ $\left.J_{5,6}=6.32 \mathrm{~Hz}, 2 \mathrm{H}, \mathrm{H}-3,5\right)$; HPLC: $\mathrm{R}_{\mathrm{t}}=14.82 \mathrm{~min}$.

\section{Biological activity}

After preparation of the novel AChE reactivator, its reactivation potency was tested using a standard in vitro screening test. Its setup (including the right concentration choice) is described in detail in our previous article [30]. GA and GF were used as nerve agent family members to see whether the new reactivator is able to reactivate both GA and GF-inhibited AChE.

\section{Acknowledgements}

The authors express their appreciation to Ms. Petra Hanusova for her technical assistance. The work was supported by the Ministry of Defence of Czech Republic (grant No. FVZ0000604).

\section{References and Notes}

1. Bajgar, J. Organophosphates/nerve agent poisoning: mechanism of action, diagnosis, prophylaxis, and treatment. Adv. Clin. Chem. 2004, 38, 151-216.

2. Tu, A.T. Chemical Terrorism: Horrors in Tokyo Subway and Matsumoto City.; Alaken Inc.: Fort Collins, CO, 2002. 
3. Matousek, J. Health and environmental threats associated with the destruction of chemical weapons. Ann. N. Y. Acad. Sci. 2006, 1076, 549-558.

4. Poziomek, E. J.; Hackley, B. E.; Steinberg, G. M. J. Pyridinium aldoximes. J. Org. Chem. 1958, 23, 714-717.

5. Lüttringhaus, A.; Hagedorn, I. Quaternary hydroxyiminomethylpyridinium salts. The dischloride of bis-(4-hydroxyiminomethyl-1-pyridinium-methyl)-ether (Lueh6), a new reactivator of acetylcholinesterase inhibited by organic phosphoric acid esters. Arzneimittelforschung 1964, 14, $1-5$.

6. Hagedorn, I.; Gündel, W. H.; Schoene, K. Reactivation of phosphorylated acetylcholine esterase with oximes: contribution to the study of the reaction course Arzneimittelforschung 1969, 19, 603606.

7. Krejcova, G.; Kuca, K.; Sevelova, L. Cyclosarin-An Organophosphate Nerve Agent. Def. Sci. J. 2005, 55, 105-115.

8. Musilek, K.; Kuca, K.; Jun, D.; Dolezal, M. Progress in synthesis of new acetylcholinesterase reactivators in period 1990-2004. Curr. Org. Chem. 2007, 11, 229-238.

9. Musilek, K.; Lipka, L.; Racakova, V.; Kuca, K.; Jun, D.; Dohnal, V.; Dolezal, M. New methods in synthesis of acetylcholinesterase reactivators and evaluation of their potency to reactivate cyclosarin-inhibited AChE. Chem. Pap. 2006, 60, 48-51.

10. Eyer, P.; Szinicz, L.; Thiermann, H.; Worek, F.; Zilker, T. Testing of antidotes for organophosphorus compounds: Experimental procedures and clinical reality. Toxicology 2007, 233, 108-119.

11. Kuca, K.; Cabal, J.; Musilek, K.; Jun, D.; Bajgar, J. Effective bisquaternary reactivators of tabuninhibited AChE. J. Appl. Toxicol. 2005, 25, 491-495.

12. Szinicz, L.; Worek, F.; Thiermann, H.; Kehe, K.; Eckert, S.; Eyer, P. Development of antidotes: Problems and strategies. Toxicology 2007, 233, 23-30.

13. Yang, G.Y.; Yoon, J.H.; Seong, C.M.; Park, N.S.; Jung, Y.S. Synthesis of bis-pyridinium oxime antidotes using bis(methylsulfonoxymethyl) ether for organophosphate nerve agents. Bull. Korean Chem. Soc. 2003, 24, 1368-1370.

14. Park, N.-J.; Jung, Y.-S.; Musilek, K.; Jun, D.; Kuca, K. Potency of several structurally different acetylcholinesterase reactivators to reactivate house fly and bovine acetylcholinesterases inhibited by paraoxon and DFP. B. Korean Chem. Soc. 2006, 27, 1401-1404.

15. Chennamaneni, S.R.; Vobalaboina, V.; Garlapati, A. Quaternary salts of 4,3' and 4,4' bispyridinium monooximes: synthesis and biological activity. Bioorg. Med. Chem. Lett. 2005, 15, 3076-3080.

16. Srinivas Rao, C.; Venkateswarlu, V.; Achaiah, G. Quaternary salts of 4,3' and 4,4' bis-pyridinium monooximes. Part 2: synthesis and biological activity. Bioorg. Med. Chem. Lett. 2006, 16, 21342138.

17. Musilek, K.; Kuca, K.; Jun, D.; Dohnal, V.; Dolezal, M. Synthesis of a novel series of bispyridinium compounds bearing a xylene linker and evaluation of their reactivation activity against chlorpyrifos-inhibited acetylcholinesterase. J. Enzym. Inhib. Med. Chem. 2005, 20, 409415. 
18. Musilek, K.; Kuca, K.; Jun, D.; Dohnal, V.; Dolezal, M. Synthesis of the novel series of bispyridinium compounds bearing (E)-but-2-ene linker and evaluation of their reactivation activity against chlorpyrifos-inhibited acetylcholinesterase. Bioorg. Med. Chem. Lett. 2006, 16, 622-627.

19. Musilek, K.; Holas, O.; Kuca, K.; Jun, D.; Dohnal, V.; Dolezal, M. Synthesis of asymmetrical bispyridinium compounds bearing cyano-moiety and evaluation of their reactivation activity against tabun and paraoxon-inhibited acetylcholinesterase. Bioorg. Med. Chem. Lett. 2006, 16, 5673-5676.

20. Musilek, K.; Holas, O.; Kuca, K.; Jun, D.; Dohnal, V.; Opletalova, V.; Dolezal, M. Novel series of bispyridinium compounds bearing a (Z)-but-2-ene Linker - Synthesis and evaluation of their reactivation activity against tabun and paraoxon-inhibited acetylcholinesterase. Bioorg. Med. Chem. Lett. 2007, 17, 3172-3176.

21. Oh, K.A.; Yang, G.Y.; Jun, D.; Kuca, K.; Jung, Y.S. Bis-pyridiumaldoxime reactivators connected with $\mathrm{CH} 2 \mathrm{O}(\mathrm{CH} 2) \mathrm{O}$ OCH2 linkers between pyridinium rings and their reactivity against VX. Biorg. Med. Chem. Lett. 2006, 16, 4852.

22. Odzak, R.; Calic, M.; Hrenar, T.; Primozic, I.; Kovarik, Z. Evaluation of monoquaternary pyridinium oximes potency to reactivate tabun-inhibited human acetylcholinesterase. Toxicology 2007, 233, 85-96.

23. Kuca, K.; Bielavsky, J.; Cabal, J.; Bielavska, M. Synthesis of a potential reactivator of acetylcholinesterase-1-(4-hydroxyiminomethylpyridinium)-3-(carbamoylpyridinium)-propane dibromide Tetrahedron Lett. 2003, 44, 3123-3125.

24. Kuca, K.; Kassa J. In vitro reactivation of acetylcholinesterase using the oxime K027. Vet. Hum. Toxicol. 2004, 46, 15-18.

25. Calic, M.; Lucic Vrdoljak, A.; Radic, B.; Jelic, D.; Jun, D.; Kuca, K.; Kovarik, Z. In vitro and in vivo evaluation of pyridinium oximes: mode of interaction with acetylcholinesterase, effect on tabun- and soman-poisoned mice and their cytotoxicity. Toxicology, 2006, 219, 85-96.

26. Lucic-Vrdoljak, A.; Calic, M.; Radic, B.; Berend, S.; Kuca, K.; Kovarik, Z. Pretreatment with pyridinium oximes improves antidotal therapy against tabun poisoning. Toxicology. 2006, 228, 41-50.

27. Kassa, J.; Kuca, K.; Cabal, J.; Paar, M. A comparison of the efficacy of new asymmetric bispyridinium oximes (K027, K048) with currently available oximes against tabun by in vivo methods. J. Toxicol. Environ. Health A. 2006, 69, 1875-1882.

28. Kuca, K.; Cabal, J.; Jun, D.; Bajgar, J.; Hrabinova, M. Potency of new structurally different oximes to reactivate cyclosarin inhibited-human brain acetylcholinesterases. J. Enzyme Inhib. Med. Chem. 2006, 21, 6636-666.

29. Musilek, K.; Kuca, K.; Jun, D.; Dolezal, M. Synthesis of bispyridinium compounds bearing propane linker and evaluation of their reactivation activity against tabun- and paraoxon-inhibited acetylcholinesterase. Lett. Org. Chem. 2006, 3, 831-835.

30. Kuca, K.; Cabal J. Evaluation of newly synthesized reactivators of the brain cholinesterase inhibited by sarin nerve agent. Toxicol. Mech. Meth. 2005, 15, 247-252.

31. Bajgar, J.; Fusek, J.; Kuca, K.; Bartosova, L.; Jun, D. Treatment of organophosphate intoxication using cholinesterase reactivators: facts and fiction. Mini-Rev. Med. Chem. 2007, 7, 461-466. 
32. Kuca, K.; Jun, D.; Musilek, K. Structural requirements of acetylcholinesterase reactivators. MiniRev. Med. Chem. 2006, 6, 269-277.

33. Kuca, K.; Jun, D.; Musilek, K.; Bajgar, J. Reactivators of tabun-Inhibited tcetylcholinesterase: Structure biological activity relationship. Front. Drug Des. Discov. 2007, 3, 381-394.

34. Ekstrom, F.; Akfur, C.; Tunemalm, A.K.; Lundberg, S. Structural changes of phenylalanine 338 and histidine 447 revealed by the crystal structures of tabun-inhibited murine acetylcholinesterase. Biochemistry 2006, 45, 74-81.

35. Ekstrom, F.; Pang, Y.P.; Boman, M.; Artursson, E.; Akfur, C.; Borjegren, S. Crystal structures of acetylcholinesterase in complex with HI-6, Ortho-7 and obidoxime: structural basis for differences in the ability to reactivate tabun conjugates. Biochem Pharmacol. 2006, 72, 597-607.

Sample Availability: Samples of compounds 1-6 are available from authors.

(C) 2007 by MDPI (http://www.mdpi.org). Reproduction is permitted for noncommercial purposes. 